\title{
Methods of Analysis of Lisinopril: A Review
}

\author{
Wajiha Gul ${ }^{1 *}$, Zarnab Augustine ${ }^{2}$, Sidra khan², Kiran Saeed ${ }^{2}$ and Hira Raees ${ }^{2}$ \\ ${ }^{1}$ Dow University of Health Sciences, Dow College of Pharmacy, Karachi, Pakistan \\ ${ }^{2}$ Faculty of Pharmacy, Jinnah University for Women, Karachi, Pakistan
}

\begin{abstract}
Lisinopril is an (ACE) angiotensin-converting enzyme inhibitor and is used in the treatment of high blood pressure, heart failure, and heart attacks. Numerous analytical methods have been developed for the determination of lisinopril. These methods include Chromatographic methods, UV spectrophotometric methods, IR, Polarographic, Stress degradation, titration and assay. This review outlines the applications of these techniques for the determination of lisinopril in pharmaceutical preparations.
\end{abstract}

Keywords: Chromatographic; Infrared (IR); Lisinopril; Polarographic; Spectrometric; Titration

\section{Introduction}

Lisinopril is an oral long-acting angiotensin converting enzyme inhibitor. It is a lysine-derivative of Enalprilate and has structural similarity with its substrate. It differs from captopril by lacking the sulfhydryl group [1,2]. Lisinopril is chemically described as (S)-1-[N2(1-carboxy-3-phenylpropyl)-L-lysyl]-Lproline dihydrate. Its empirical formula is $\mathrm{C} 21 \mathrm{H} 31 \mathrm{~N} 3 \mathrm{O} 5.2 \mathrm{H} 2 \mathrm{O}$.

Lisinopril is used in high blood pressure (hypertension), congestive heart failure, and in heart attack, also in renal and retinal complications of diabetes [2]. It also exhibits haemodynamic effects [3]. It is an active site directed inhibitor [4]. It promotes natriuresis and useful in preventing diabetic retinopathy in the patients of type II diabetes $[4,5]$.

Its onset of action is 1-2 hours. Duration of action is 24 hours. Absorption of the lisinopril is slowly and moderately from GI tract (oral) and peak plasma concentration obtain after 7 hours. It has no interactions with drugs and foods. The drug distribution is up to $25 \%$. It is excreted unchanged in urine and does not undergo metabolism. The drug is given orally in case of hypertension. Adult dose is initially 5-10 $\mathrm{mg}$ daily given at bedtime. Dose of drug in renovascular hypertension, volume depletion, severe hypertension in the beginning $2.5-5 \mathrm{mg}$ once daily. In diuretic patients $5 \mathrm{mg}$ once daily. Maintenance dose is 20 $\mathrm{mg}$ once daily up to $80 \mathrm{mg}$ daily can be given. In case of children $\geq 6$ years: initially up to $0.07 \mathrm{mg} / \mathrm{kg}$ (up to $5 \mathrm{mg}$ once daily) can be given. Bioavailability of the drug is about $25 \%$ (Figure 1) [6].

\section{Properties of lisinopril}

Lisinopril is a white, crystalline powder, having a molecular weight of 441.52 and molar mass of $40.488 \mathrm{~g} / \mathrm{mol}$. Lisinopril is a white to off-white, crystalline powder, with a molecular weight of 441.53 . It

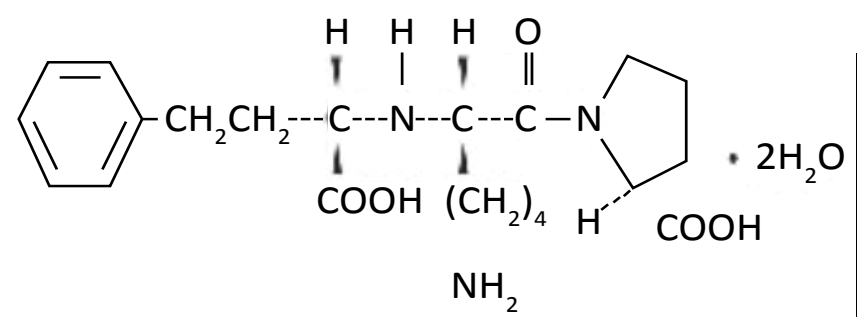

Figure 1: Chemical structure of lisinopril. is soluble in water and sparingly soluble in methanol and practically insoluble in ethanol, acetone, acetonitrile and chloroform [7].

\section{Analytical Method}

Literature review shows that there are developed methods including spectrophotometric, atomic absorption, HPLC and LC-MS method for the estimation of lisinopril [8].

The official analytical methods for Lisinopril described are potentiometric titration and HPLC various spectrophotometric methods, chromatographic methods of analysis such as micellar electrokinetic chromatography and gas liquid chromatography $[9,10]$, Capillary electrophoresis, fluoroimmunoassay, radioimmunoassay and fluoroenzymatic assay have also been reported [11,12].

The available methods are associated with drawbacks such as low reliability due to isomerisation, less sensitive, measurement at lower wavelength, $\mathrm{pH}$ dependent, inaccessibility and requirement of expertise [13].

Literature survey reveals the availability of several methods by using various mixtures but no method was available on the mixture of distilled water and methanol 70:30 which was an unique method with better results [14].

Analytical data are used to screen the potential drugs in biological samples, support formulation. Studies assist in the development of medicine production, monitor the (API) bulk pharmaceuticals and finished products and also test final products for release [2].

\section{Methods of Estimation for Lisinopril}

There are various methods of analysis for lisinopril described in literature as,

*Corresponding author: Wajiha Gul, Dow University of Health Sciences, Dow College of Pharmacy, Karachi, Pakistan, Tel: +92 21 36620857; E-mail: wajihanasheed_05@hotmail.com

Received November 17, 2016; Accepted December 12, 2016; Published January 04, 2017

Citation: Gul W, Augustine Z, Khan S, Saeed K, Raees H (2017) Methods of Analysis of Lisinopril: A Review. J Bioequiv Availab 9: 331-335. doi: 10.4172/ jbb. 1000320

Copyright: $\odot 2017 \mathrm{Gul} \mathrm{W}$, et al. This is an open-access article distributed under the terms of the Creative Commons Attribution License, which permits unrestricted use, distribution, and reproduction in any medium, provided the original author and source are credited. 
1) UV-visible spectroscopic methods

2) Spectrofluorimetric methods of estimation by reaction modifications

3) High performance liquid chromatographic methods

4) Combination of methods or techniques

5) Titrimetric methods

6) Miscellaneous methods

\section{UV-visible spectroscopic methods}

There are developed Spectrophotometric methods of analysis in single or in combination. Lisinopril shows absorption in UV-visible range in alkaline media produced by sodium hydroxide measured by absorption maxima method [15-17].

Quantitative estimation of Lisinopril in bulk and its marketed formulations by simple and sensitive UV spectrophotometric method have been developed which is accurate and economical.

Spectrophotometric method have been developed to determine the Lisinopril in unadulterated form or in formulation by coupling with o-phenylendiamine to convert the Lisinopril to a more sensitive form which can be measured in Visible region its by using aqueous solvents.

The spectrophotometric method developed includes the degradation of Lisinopril to produce diketopiperazine, by the sodium hypochlorite solution in the alkaline media. Then subjected to condensation with o-Phenylendiamine to form complex showing reddish-yellow color. The diketone-o phenylendiamine complex formed is soluble in acidic and basic solvents. It has been determined by spectrophotometrically at $\lambda \max 399.5 \mathrm{~nm}$ in alkaline media and displays linearity with Beer's range of $2 \mu \mathrm{g}$ to $30 \mu \mathrm{g}$, the factors like temperature, reaction duration, $\mathrm{pH}$ of solvent are optimized. The method has been validated according to ICH Guidelines [18].

\section{Spectrofluorimetric methods of estimation by reaction modifications}

Lisinopril is non-fluorescent drug which is converted into fluorescent derivative. Fluorimetric method is based upon the condensation reaction between primary amino group of Lisinopril and Fluorescien to form fluorescent derivative (LSFN) in methanol at $60^{\circ} \mathrm{C}$ for $5 \mathrm{~min}$. The formation of fluorescent derivative can be determined by the UV ( $\lambda \max 227 \mathrm{~nm}$ ), NMR, Mass and IR spectra [13]. Spectrofluorimetric methods are used to estimate lisinopril present in small quantities i.e. in nanogramms in blood or plasma; these are frequently based upon coupling reactons with fluorephores. The saga of the development of analytical methods for lisinopril has shown the various phases of technical advancements in analytical field with respect to Lisinopril [15].

Reported estimation of Lisinopril in pharmaceutical tablets using sequential injection analysis by spectrofluorimetric method based upon the reaction between Lisinopril and o-phthalaldhyde in presence of 2-mercaptoethanol (borate buffer medium, $\mathrm{pH}=10.6$ ), calculated at excitation wavelength of $346 \mathrm{~nm}$ and emission at $455 \mathrm{~nm}$ [19].

\section{High performance liquid chromatographic methods}

HPLC methods have been widely been used for the determination of lisinopril. We used HPLC method because these are simple, accurate, and precise and time consuming. Determination of lisinopril in dosage forms in addition to spiked human plasma by using solid phase extraction was carried out by spectrophotometry and reversed-phase HPLC. The recommended methods were applied without any intrusion in dosage forms, either alone or co-formulated for the determination of lisinopril with hydrochlorothiazide. In addition, HPLC method was expanded to the in vitro determination of the drug in spiked human plasma [17,20,21].

Lisinopril is very useful in antihypertensive and statins as cholesterol lowering drug. By using RP-HPLC method simultaneous determination of lisinopril with pravastatin, atorvastatin, and rosuvastatin was done. Application of the proposed method was successfully applied to the determination of these compounds in pharmaceutical preparations because of their high percentage of recovery, good accuracy and precision [22].

Beasle et al. described and validate a stability-indicating HPLC method for lisinopril, lisinopril degradation product, methyl and propyl paraben in extemporaneous formulation of lisinopril [23].

RP- HPLC procedures were developed to provide a single, symmetric peak for each drug like angiotensin-converting enzyme (ACE), ramipril, enalapril maleate, benazepril lisinopril and quinapril. The HPLC method using Hypersil silica column and mobile phase consisting of methanol-water-triethylamine (50:50:0.1 v/v) and quantitation evaluation was achieved with UV detection at $210 \mathrm{~nm}$ $[24,25,18]$.

HPLC method was validated and applied for the simultaneous determination of lisinopril and NSAIDs in bulk, pharmaceuticals formulations and human serum. The quantitative was achieved at 225 $\mathrm{nm}$ having flow rate of $1.0 \mathrm{ml} / \mathrm{min}$. Suitability of this method for the quantitative determination of the drugs was proved by validation in accordance with International Conference on Harmonization (ICH) guidelines. The method is precise and accurate and can be used for analysis of pharmaceutical preparations in quality control (QC) and clinical laboratories [26].

The aim of this research was to study and to standardize a HPLC and absorbance ratio method for the determination of hydrochlorothiazide and lisinopril in commercially available pharmaceutical dosage forms. An HPLC method has been developed for the simultaneous determination of hydrochlorothiazide and lisinopril from formulations, using acetonitrile:water $(20: 80 \mathrm{v} / \mathrm{v})$ as a mobile phase and flow rate of $1.0 \mathrm{ml} / \mathrm{min}$. The determination of hydrochlorothiazide and lisinopril was performed by using the absorbance read at $272.0 \mathrm{~nm}, 258.8 \mathrm{~nm}$ and $262.7 \mathrm{~nm}$ in the zero-order spectra of their mixture [27].

An isocratic RP-HPLC method has been developed for the simultaneous determination of lisinopril and $\mathrm{H} 2$ antagonists in bulk, dosage formulations, and human serum at $225 \mathrm{~nm}$. Limit of detection (LOD) and limit of quantitation (LOQ) were in the ranges of 0.07-10.4 $\mathrm{ng} / \mathrm{ml}$. Both intra- and inter-day precision and accuracy results were 98.0-102\% [28].

Arayne et al. developed HPLC method for simultaneous determination of Metformin and ACE inhibitors like lisinopril, captopril, etc and its degradable product in bulk drugs, pharmaceutical products and in human serum. The analytes peaks were observed at $218 \mathrm{~nm}$. The developed method was successfully applied to quantitate metformin, lisinopril, captopril, and enalapril in pharmaceutical formulations and human serum [29].

In this study, a sensitive, specific, precise and accurate method for lisonopril quantitative determination in human serum was developed 
and validated. The mean recovery of lisinopril from serum samples was $88 \%$. The LOQ for lisinopril was $6 \mathrm{ng} / \mathrm{ml}[30]$.

\section{Combination of methods or techniques}

By using HPLC (high-performance liquid chromatography) a new method was developed in which impurities in the bulk lisinopril drug was differentiate, In which mobile phase used in a ratio of $5 \%(\mathrm{v} / \mathrm{v})$ acetonitrile and 95\% (v/v) aqueous buffer and Detection was carried out at $210 \mathrm{~nm}$ later on by merge with the FT-ICRMS and NMR data, structures of unknown impurities were also found [17]. In another method isomerization of lisinopril has been studied by using HPLC, NMR, and DFT. It shows that $77 \%$ Trans and $23 \%$ cis was eluted [21].

Another sensitive and precise HPLC method with fluorimetric detection has been developed for the assay of lisinopril in human plasma and urine. The reaction mixture was chromatographed on C18column with gradient elution, using methanol and $0.02 \mathrm{M}$ phosphate buffer $\mathrm{pH}$ 3.2. The mean recovery of lisinopril from plasma and urine was 63.41 and $74.08 \%$, respectively [25].

Another simple and sensitive liquid chromatography tandem multiple-stage mass spectrometry (HPLC/MS/MS) method that is suitable for bulk lisinopril analysis was developed, by which lisinopril and its RSS isomer were separated and differentiated. LC-UV scan of lisinopril revealed the presence of an unknown impurity $(\sim 0.14 \%)$ at a relative retention time RT of $3.26 \mathrm{~m}$ using phosphate bufferacetonitrile as binary gradient system. The impurity was isolated by HPLC employing a linear gradient of water and acetonitrile [31,32].

The establishment of structures as well as quantification and characterizations of degraded products were carried out by sophisticated instrumental methods like UV, IR, and RP-HPLC. Furthermore, the mechanism of degradation was verified by GC-MS studies [33].

\section{Titrimetric methods}

Different titrimetric method for analysis of Lisinopril is carried out in which include following: In the middle of 18 century there was origin of titrimetric method of analysis. In 1835 Gay-Lussac invented the volumetric methods which actually lead to the foundation of the term titration. While the assay method is very old yet but certain signs of some renovation may including as dispersion to non-aqueous titrations, intensifying the field of application to weak acids and bases as well as to detection of potentiometric end point improving the accuracy of the methods. Simultaneously detection of group analysis procedures, in which titrimetric methods play a vital role in establish reaction rates. The main advantages of this method are time saving and labor with high precision and the fact that there is no need of using reference standards. Titrimetric methods have been used for the determination of lisinopril 1 in commercial dosage forms. Furthermore, it may widely uses for drug estimation; titrimetry has also been used for the estimation of degradation products of the pharmaceuticals [34-37].

Different simple titrimetric procedures are described for the determination of lisinopril (LNP) in bulk and in pharmaceutical that depend on the neutralization of basic-amino and acidic carboxylic acid groups present in LNP. In titrimetric studies have been applied in different range of concentration as $2.0-15 \mathrm{mg}$ of lisinopril (LNP) this established method for determination LNP in tablets and as well as the results were validated statistically by comparing the results with those of the reference method by applying the Student's t-test and F-test. The accuracy precision of the methods were evaluated further determine by recovery studies via standard addition technique $[9,38]$.
Another advance method in which using copper (II) phosphate for the determination of lisinopril by anodic stripping voltammetric assay. In this method of analysis different experimental parameters have been carefully premeditated and fully validated. The method has been helpful effectively for the determination of the drugs in their pharmaceutical preparations as well as in plasma. The acquired results were compared statistically with those obtained from the official USP methods as well as in case of AS published method [39].

\section{Miscellaneous methods}

Lisinopril have been finding out in different dosage form and also in biological fluids by highly sensitive and simple polarographic method. In this method, dealing of the compound with nitrous acid as a result measuring the cathodic current produced by the resulting nitroso derivative. The polarographic behavior was calculated as adopting direct current (DCt), differential pulse (DP) and alternating current $(\mathrm{ACt})$ polarography along with well define $\mathrm{pH}$ range of 1.0-8.0 was achieved in Britton-Robinson buffers (BRb). This method may also be performed for determination of lisinopril in spiked human urine and plasma [18].

Another approach has been developed for analysis of lisinopril (LIS) in pharmaceutical formulations using a tris $\left(2,2^{\prime}\right.$-bipyridyl)ruthenium (II) (Ru (bipy) 32+) peroxydisulfate chemiluminescence (CL) system in a two chip device. This is an ideal, rapid, selective and sensitive method including parameters like flow rates, $\mathrm{pH}$, and concentration of reagents were carefully optimized under influence the CL signal intensity. This method is consider as one the best method for analysis of LIS in pharmaceutical products and was establish to be free from any hindrance of acid-induced degradation (AID) products and other ingredients frequently present in these preparations [40].

By using Spectrophotometric and polarographic technique determination of lisinopril has been established using 2, 4-dinitrofluorobenzene by formation of colored products and polarographically active derivatives. In this study methods have been validated and optimized by different experimental conditions which may be pertain to the determination of lisinopril in their commercial scale tablets. Comparative statistical analysis has been recognized by means of the authorized HPLC methods [41].

A novel method for the quantitative determination of the angiotensin-converting enzyme inhibitor lisinopril in human plasma have been established by mean of negative ion chemical ionization mass spectrometry and gas chromatography [42].

Other method with respect to chemical nature the drug may also act as photosensitive behavior as go through hydrolysis and oxidized in presence of oxygen. Due to respect of stress degradation of lisinopril certain studies have been conducted under different conditions recommended by International Conference on Harmonization (ICH) in which objective of study as to find out the pathway for stress degradation of Lisinopril in bulk [43].

\section{Conclusion}

The analytical methods always accentuate for the simplicity, accuracy, precision, and specificity. Analytical method development mainly involves developing method having advantages over existing methods. High pressure liquid chromatography HPLC methods required costly equipment, labor intensive sample preparation procedure and the personal skilled in chromatographic techniques most of the HPLC methods reviewed have the prospective application 
Citation: Gul W, Augustine Z, Khan S, Saeed K, Raees H (2017) Methods of Analysis of Lisinopril: A Review. J Bioequiv Availab 9: 331-335. doi: $10.4172 / \mathrm{jbb} .1000320$

to clinical research of multi-drug pharmacokinetics, drug combination studies and also for interaction studies.

The analytical methods developed for lisinopril show that the former analytical methods developed for lisinopril evaluation in single or in combination formulations reveal the development of spectrophotometric and fluorimetric methods based coupling reactions followed by chromatographic methods. The other methods such as capillary electrophoresis, fluoroimmunoassay, radio immunoassay and fluoro enzymatic assay have also been reported. The development of each method indicates the overcoming of the limitations of the existing methods and making availability of better methods.

\section{References}

1. Sultana N, Arayne MS, Siddiqui R, Naveed S (2012) RP-HPLC Method for the Simultaneous Determination of Lisinopril and NSAIDs in API, Pharmaceutical Formulations and Human Serum. American Journal of Analytical Chemistry 3: $147-152$

2. Naveed S (2014) Analytical determination of lisinopril using UV spectrophotometer and HPLC: An Overview. Mod Chem appl 2: 137.

3. Merck Research Laboratories (2001) The Merck Index, 13th Edn., Merck \& Co., White House Station, NJ, USA, pp: 989 \& 86.

4. Beale JM, Block JH (2004) Wilson and Gisvold's Text book of organic medicinal and pharmaceutical chemistry, 11th Edn, Lippincott-Williams \& Wilkins, Philadelphia, USA, pp: 645 \& 631

5. Sharma HL, Sharma KK (2012) Principles of pharmacology, $2^{\text {nd }}$ Edn, Paras's medical publishers, Delhi, pp: 255 \& 284.

6. Audu SA, Taiwo AE, Waziri FI, Ojuolape AR, Sani AS, et al. (2012) Comparative evaluation study on different brands of lisinopril tablet using hplc and uv spectrophotometer. Journal of Natural Sciences Research 2: 18-25.

7. Chavan V, Phasate P (2015) Development and validation of a UV spectrophotometric method for the determination of lisinopril both in bulk and marketed dosage formulations. Int J Pharm Sci Res (IJPSR) 6: 394-397.

8. Preetham DN, Sujana K, Sankar PDS (2014) Development and validation of UV spectrophotometric method for the estimation of lisinopril in bulk and pharmaceutical formulation. Int J Pharm Sci Rev Res 25: 257-259.

9. Sagirli O, Ersoy L (2004) An HPLC method for the determination of lisinopril in human plasma and urine with fluorescence detection. J Chromatogr 809: $159-165$

10. Ivanovic D, Medenica M, Jancic B, Knezevic N, Malenovic A, et al. (2007) Validation of an analytical procedure for simultaneous determination of hydrochlorothiazide, lisinopril, and their impurities. Acta Chromatogr 18: 143156

11. Yuan AS, Gilbert JD (1996) Time-resolved fluoro-immunoassay for the determination of lisinopril and enalaprilat in human serum. J Pharm Biomed Anal 14: 773-781.

12. Gotti R, Andrisano V, Cavrini V, Bertucci C, Furlanetto S (2000) Analysis of ACE-inhibitors by CE using alkylsulfonic additives. J Pharm Biomed Anal 22: 423-431.

13. Jamakhandi CM, Javali C, Kumar S, Kumar S, Kumar SDS (2010) New fluorimetric method of determination for lisinopril dosage forms. Int J Pharma Sci Drug Res 2: 182-187.

14. Zaheer Z, Khan S, Sadeque M, Baig MS, Sangshetti JN (2016) Development and validation of UV spectrophotometric estimation of lisinopril dihydrate in bulk and tablet dosage form using area under curve method. JIAPS 1:12-16.

15. Jamkhandi CM, Javali C, Niranjan MS (2011) Developed analytical methods for lisinopril-An ace inhibitor. Asian Journal of Biochemical and Pharmaceutical Research 1: 1-8.

16. Stanisz B (2004) Estimation of the applicability of differential spectroscopic method for the determination of lisinopril in tablets and for the evaluation of its stability. Acta Pol Pharm 61: 327-334.

17. Rahman N, Anwar N, Kashif M (2005) Application of pi-acceptors to the spectrophotometric determination of lisonopril in dosage forms. Farmaco 60: 605-611.
18. El-Gindy A, Ashour A, Abdel-Fattah L, Shabana MM (2001) Spectrophotometric spectroflourometric and LC determination of lisinopril. J Pharm Biomed Anal 25: 913-931.

19. Constantinos KZ, Paraskevas DT, Demtrius GT, Georgios AT, Anastasios E, et al. (2004) Rapid spectrofluorimetric determination of lisinopril in pharmaceutical tablets using sequential injection analysis. Anal Bioanal Chem 379: $759 \square 763$.

20. Siddiqui MR, Al-Othman ZA, Rahman N (2013) Analytical techniques in pharmaceutical analysis: A review. Arabian J Chem.

21. Rahman N, Siddiqui MR, Azmi SNH (2007) Spectrophotometric determination of lisinopril in commercial dosage forms using $\mathrm{N}$-bromosuccinimide and chloranil. Chemia analityczna 52: 465-480.

22. Rahman N, Singh M, Hoda M (2005) Optimized and validated spectrophotometric methods for the determination of lisinopril in pharmaceutical formulations using ninhydrin and ascorbic acid. J Braz Chem Soc 16: 1001-1009.

23. Matei N, Birghila S, Popescu V, Dobrinas S, Soceanu A, et al. (2008) Kinetic study of vitamin $\mathrm{C}$ degradation from pharmaceutical products. Rom J Phys 53 343-351.

24. Basavaiah K, Tharpa K, Vinay KB (2010) Titrimetric assay of lisinopril in aqueous and non-aqueous media. Eclet Quím 35: 7-14.

25. 25 Tuse SK, Vadgaonkar AR, Musmade DS, Kasture VS (2014) Stress degradation of Lisinopril as per ICH Guidelines \& Characterisation. IJAPA 4: 47-52.

26. 26El-Enany N, Belal F, Al-Ghannam S (2003) Polarographic determination of lisinopril in pharmaceuticals and biological fluids through treatment with nitrous acid. Microchimica Acta 141: 55-61.

27. El-Gindy A, Al-Lawati HA, Al-Azwani M, Varma GB, Suliman FEO, Al-Kindy SM (2012) Towards an ideal method for analysis of lisinopril in pharmaceutical formulations using a tris (2, 2'-bipyridyl)-ruthenium (II)-peroxydisulfate chemiluminescence system in a two-chip device. Analytical Methods 4: 773-779.

28. Razak OA, Belal SF, Bedair MM, Barakat NS, Haggag RS (2003) Spectrophotometric and polarographic determination of enalapril and lisinopril using 2, 4-dinitrofluorobenzene. J Pharm Biomed Anal 31: 701-711.

29. Leis HJ, Fauler G, Raspotnig G, Windischhofer W (1999) An improved method for the measurement of the angiotensin-converting enzyme inhibitor lisinopril in human plasma by stable isotope dilution gas chromatography/negative ion chemical ionization mass spectrometry. Rapid Commun Mass Spectrom 13: 650-653.

30. Razak OA, Belal SF, Bedair MM, Haggag RS (2003) The utilization of copper (II) phosphate for the anodic stripping voltammetric assay of alendronate sodium, desferrioxamine mesylate and lisinopril. Talanta 59: 1061-1069.

31. Zhu PX, Wang DH, Sun CR, Shen ZQ (2008) Characterization of impurities in the bulk drug lisinopril by liquid chromatography/ion trap spectrometry. J Zhejiang Univ Sci B 9: 385-390.

32. Bouabdallah S, Ben Dhia MT, Driss MR (2014) Study of a conformationa equilibrium of lisinopril by HPLC, NMR, and DFT. Int J Anal Chem 2014: 494719.

33. 33 El-Emam AA, Hansen SH, Moustafa MA, El-Ashry SM, El-Sherbiny DT, et al. (2004) Determination of lisinopril in dosage forms and spiked human plasma through derivatization with 7-chloro-4-nitrobenzo-2-oxa-1, 3-diazole (NBD-Cl) followed by spectrophotometry or HPLC with fluorimetric detection. J Pharm Biomed Anal 34: 35-44.

34. Sultana N, Arayne MS, Safila N (2011) Validated method for the simultaneous determination of lisinopril, pravastatin, atorvastatin and rosuvastatin in API, formulations and human serum by RP-HPLC. Chin J Polym Sci 29: 1216-1220.

35. 35 Beasley CA, Shaw J, Zhao Z, Reed RA (2005) Development and validation of a stability indicating HPLC method for determination of lisinopril, lisinopril degradation product and parabens in the lisinopril extemporaneous formulation. J Pharm Biomed Anal 37: 559-567.

36. Bonazzi D, Gotti R, Andrisano V, Cavrini V (1997) Analysis of ACE inhibitors in pharmaceutical dosage forms by derivative UV spectroscopy and liquid chromatography (HPLC). J Pharm Biomed Anal 16: 431-438.

37. Shinde V, Trivedi A, Upadhayay PR, Gupta NL, Kanase DG, et al. (2007) Identification of a new impurity in lisinopril. J Pharm Biomed Anal 43: 381-386.

38. Chauhan V, Prajapati ST, Patel CN (2011) A validated RP-HPLC method for simultaneous estimation of amlodipine and lisinopril in pharmaceutical dosage form. IJPSR 2: 1712-1715. 
Citation: Gul W, Augustine Z, Khan S, Saeed K, Raees H (2017) Methods of Analysis of Lisinopril: A Review. J Bioequiv Availab 9: 331-335. doi: $10.4172 / j b b .1000320$

39. Naveed S, Sultana N, Arayne MS (2012) Simultaneous determination of lisinopril and $\mathrm{H}_{2}$ antagonists in API, formulations and human serum by using two different HPLC systems. Med Chem Res 21: 4037-4042.

40. Arayne MS, Sultana N, Zuberi MH, Siddiqui FA, Haroon U (2013) Simultaneous determination of metformin, captopril, lisinopril, and enalapril by RP-HPLC: its applications in dosage formulations and in human serum. Med Chem Res 22: 5717-5722.

41. Andreas T, Bairachtari K, Georgarakis M (2003) Development of a liquid chromatography-mass spectrometry method for monitoring the angiotensinconverting enzyme inhibitor lisinopril in serum. J Chromatogr B 783: 425-432.

42. Sun C, Zhu P, Hu N, Wang D, Pan Y (2010) Differentiation of lisinopril and its RSS diastereomer by liquid chromatography combined with collision-induced dissociation mass spectrometry. J Mass Spectrom 45: 89-96.

43. Sultana N, Arayne MS, Siddiqui R, Naveed S (2012) RP-HPLC method for the simultaneous determination of lisinopril and NSAIDs in API, pharmaceutical formulations and human serum. Am J Analyt Chem 3: 147. 